\title{
SEGUINDO A ROTA DOS BARQUINHOS DE IEMANJÁ'
}

\section{Dandara Rodrigues Dorneles ${ }^{2}$}

Resumo: Este ensaio fotográfico retrata o circuito de preparação e de oferecimento dos Barquinhos de Iemanjá: pequenos barcos azuis, com aproximadamente 40 centímetros de comprimento, feitos de papelão, portando adereços, flores e comidas; que são os presentes destinados ao orixá Iemanjá pelo Centro Africano Ogum e Iansã, no Rio Grande do Sul, Brasil. Os primeiros registros desse circuito foram realizados durante a preparação dos presentes no terreiro, localizado no município de Canoas, RS, e, em seguida, continuaram durante o percurso de excursão da comunidade até a praia de Santa Terezinha, em Imbé, Litoral Norte do Rio Grande do Sul, aonde os presentes em homenagem à Iemanjá vêm sendo oferecidos anualmente. As fotos mostram as etapas ritualísticas, dotadas de complexidades, potências e magnitudes, com diferentes elementos, mãos que fazem e compóem barcos, cenas e manifestações da religiosidade afro-brasileira no Sul do Brasil.

Palavras-chave: Oferenda; Religiosidade Afro-Brasileira; Terreiro.

\section{FOLLOWING THE ROUTE OF BARQUINHOS DE IEMANJÁ}

\begin{abstract}
This photo essay portrays the circuit of preparation and offering of the Barquinhos de Iemanjá: small blue boats, approximately 40 centimeters long, made of cardboard, bearing props, flowers and food, which are the gifts destined for the orisha Iemanjá by the Centro Africano Ogum e Iansã in Rio Grande do Sul, Brazil. The first records of this circuit were made during the preparation of those gifts in the terreiro, located in the city of Canoas, Rio Grande do Sul, and continued during the excursion route of the community to Santa Terezinha beach, in Imbé, North Coast of Rio Grande do Sul, where gifts in honor of Iemanjá have been

1 Como citar: DORNELES, Dandara Rodrigues. Seguindo a rota dos barquinhos de Iemanjá. Debates do NER, Porto Alegre, v. 1, n. 37, p. 255-269, 2020.

2 Dandara Rodrigues Dorneles é mestra pelo Programa de Pós-Graduação em Educação da Universidade Federal do Rio Grande do Sul, Porto Alegre, Brasil. E-mail: dandararodrigues.d@gmail.com.
\end{abstract}

Debates do NER, Porto Alegre, Ano 20, N. 37, P. 25 5-269, Jan./JUl. 2020 
offered annually. The photos show the ritualistic stages, endowed with complexities, powers and magnitudes, with different elements, hands that make and compound boats, scenes and manifestations of Afro-Brazilian religiosity in southern Brazil.

Keywords: Offering; Afro-Brazilian Religiosity; Terreiro.

Iemanjá, um dos orixás mais cultuados no Brasil, é, no panteão afro-brasileiro $^{3}$, a rainha do mar, dona do pensamento, protetora dos marujos e pescadores (Oro; Anjos, 2009; Vallado, 2010). Sob o prisma da religiosidade afro-brasileira, os modos com que os cultos à Iemanjá são feitos no Rio Grande do Sul dependem de cada terreiro e suas formas rituais. Porém, faz parte da tradição as comunidades-terreiros irem em caravanas em direção ao litoral ou às orlas fluviais nas proximidades do dia 2 de fevereiro (Dia de Iemanjá no estado) para realizarem as suas homenagens e oferecerem seus presentes à Rainha do Mar (Corrêa, 1994; Oro; Anjos, 2009).

Segundo Mãe Ângela, iyalorixá do Centro Africano Ogum e Iansãa, "Iemanjá é uma mãe muito remosa. Ao mesmo tempo em que é mãe e cuida, dando um mar calmo e seguro, é forte, brava e geniosa. Da calmaria à ressaca 'bota pra fora', tira e leva o que quiser, inclusive seus presentes" que, no terreiro em questão, são denominados de Barquinhos de Iemanjá . Tratam-se de pequenos barcos azuis realizados manualmente, com aproximadamente 40 centímetros de comprimento, feitos de papeláo, portando adereços (brincos, colares, perfumes, pentes e espelhos), flores e comidas. Realizados de forma coletiva, ritualística, pensados em cada detalhe, desde a

3 O panteão dos orixás pode variar de acordo com cada religião afro-brasileira. No panteão do Batuque do Rio Grande do Sul são cultuados doze orixás: Bará, Ogum, Iansã ou Oiá, Xangô, Oba, Odé/Otim, Ossanha, Xapanã, Oxum, Iemanjá e Oxalá, nessa respectiva ordem (Oro, 2008).

4 Barquinhos de Iemanjá, Barquinhos da Mãe, ou simplesmente barquinhos são os termos usuais na comunidade onde os registros fotográficos foram realizados. 
aquisição dos seus itens, ${ }^{5}$ os barquinhos são preparos complexos e múltiplos em termos de sentidos, envolvendo tempo, relaçôes, porquês e fundamentos ${ }^{6}$.

Nessa direção, todo ano, no final do mês de dezembro, o Centro Africano Ogum e Iansã inicia o preparo manual e ritualístico dos Barquinhos de Iemanjá dentro do terreiro, na periferia de Canoas, RS. Em uma quinta-feira (28 de dezembro de 2017), o circuito retratado neste ensaio através da fotografia ${ }^{7}$ se iniciou.

A partir da indicação de Mãe Ângela começamos, neste dia, uma movimentação para reunir todos os papelóes que tinham no terreiro, pois o papelão é a matéria-prima principal para a confecção dos presentes. Após agruparmos a quantidade de papeláo necessária, prontamente pegamos as caixas e as desmontamos. Com o auxílio de uma mesa ou no próprio chão começamos a fazer as devidas marcaçóes através de uma régua e com a caneta na mão desenhamos os traços para os cortes.

5 Em minha dissertação de mestrado descrevo, através de uma pesquisa etnográfica, esse preparo ritualístico em maior detalhe. Apresento esses fazeres afro-religiosos no terreiro analisando alguns dos saberes que sáo invocados e ensinados em seu circuito de preparação, e justaponho tais ensinamentos às críticas desferidas a partir de certa vertente de discurso ecológico.

6 Termo êmico presente no cotidiano dos terreiros do Rio Grande do Sul.

7 Todos os registros fotográficos apresentados são de minha autoria e tiveram a liberação da comunidade do Centro Africano Ogum e Iansã para a publicaçáo.

Debates do NER, Porto Alegre, ano 20, N. 37, P. 255 -269, JAn./Jul. 2020 
Fotografia 1 - Realização das marcaçôes para os posteriores cortes e dobraduras que formarão o casco do barco de papelão ${ }^{8}$

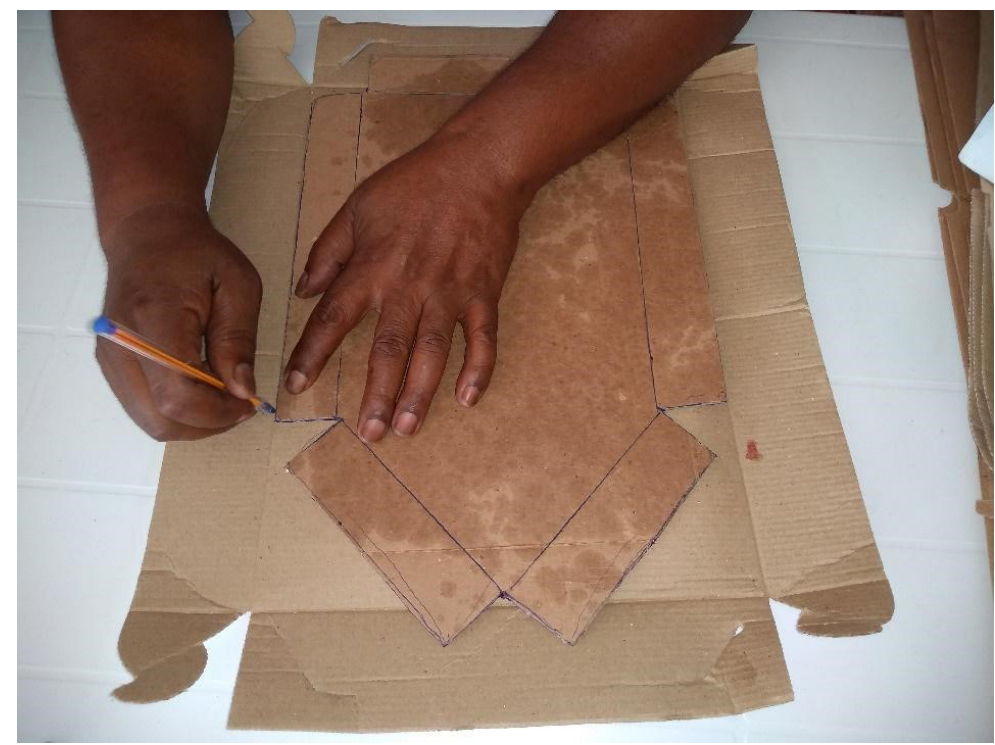

Após o desenho, outros filhos trabalharam com as tesouras e, a seguir, realizaram as dobraduras, também marcadas à caneta. Com o auxílio de fita crepe nas bordas cortadas, fomos fechando a parte de baixo do barco, formando, assim, o casco. Em seguida, ao forrar o casco com folha de ofício e enfeitar com franjas uniformes de papel seda azul claro temos, por fim, o casco dos barcos neste primeiro dia de preparação.

Nos dias que se seguem, ao cortar e colar pequenos cubos no meio do barco, temos o sustento do mastro. Ao forrar os palitos de churrasco com papel seda cortado em tiras e, posteriormente, amarrá-los com pedaços de barbante fixando-os no barco, construímos um mastro. Ao dobrar, cortar, pendurar e estender bandeirinhas de papel seda azul e branco nos palitos, temos as velas do barco. Assim, após dias e semanas de um fazer vagaroso, delicado, manual e em família, que se estendeu de dezembro a fevereiro,

8 Crédito das imagens: Acervo da autora. 
tínhamos em mãos os Barquinhos de Iemanjá, resultado das diferentes etapas que foram empreendidas sempre de forma coletiva entre os filhos, com o auxílio da Mãe de santo e dos mais velhos.

Fotografia 2 - Confecção do mastro do barco

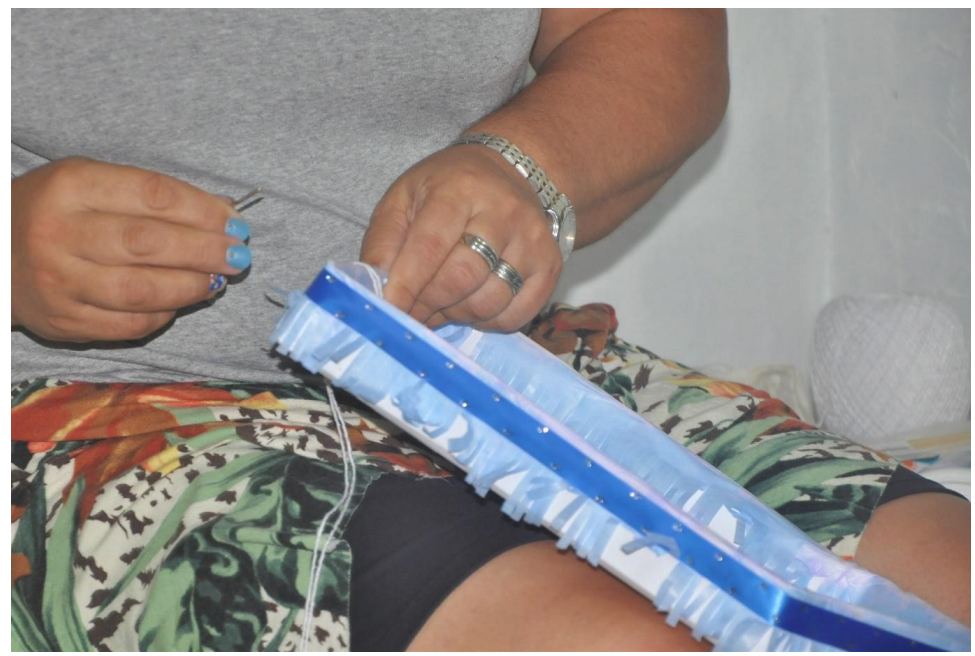

Fotografia 3 - Barcos decorados

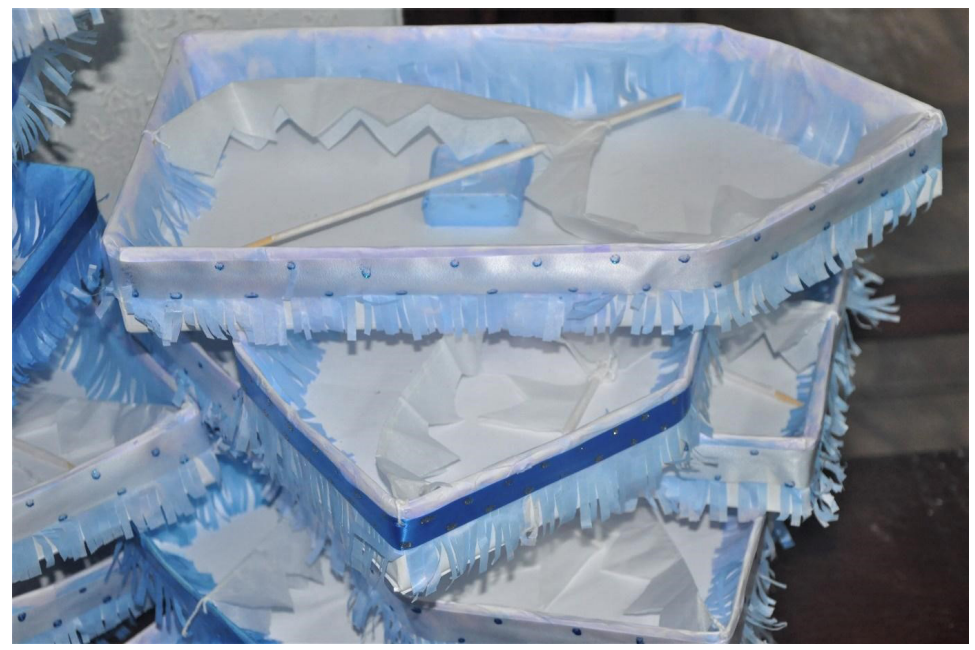

Debates do NER, Porto Alegre, ano 20, N. 37, P. 255 -269, Jan./Jul. 2020 
Dando sequência à rota dos barquinhos no Centro Africano Ogum e Iansã, após a conclusão de sua estrutura, o circuito de preparo se desdobrou no mês subsequente até o dia três de fevereiro ${ }^{9}$, data de realização da homenagem. Assim, é chegado o momento de montagem dos barcos.

Uma das filhas mais velhas do terreiro traz no início da tarde as cocadas, quindins e merengues preparados na noite anterior e armazenadas em caixas. Alguns merengues que seriam compartilhados mais tarde na festa, por exemplo, foram acondicionados, e ficaram no aguardo junto à sineta que, com seu toque, dá início aos cultos.

Fotografia 4 - Merengues acondicionados e no aguardo junto à sineta que, com seu toque, dá início ao rito de homenagem a Iemanjá

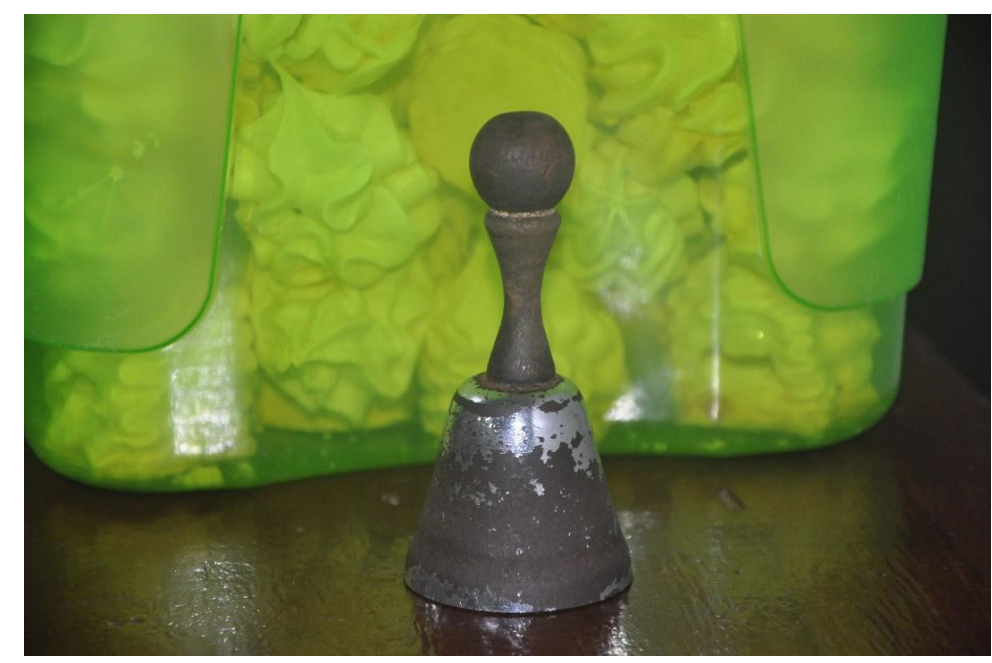

Com o passar do tempo e com a proximidade do horário programado da homenagem, os elementos para a composição dos presentes foram colocados a postos (cocada, merengue, canjica, quindim, flores, leque, pente,

9 Dia 2 de fevereiro é o Dia de Iemanjá para muitas comunidades afro-religiosas no estado do Rio Grande do Sul, porém, no Centro Africano Ogum e Iansã, as homenagens no litoral são realizadas no primeiro sábado após a data que, no ano em questão (2018), caiu em 3 de fevereiro.

Debates do NER, Porto Alegre, ano 20, N. 37, P. 255-269, JAn./Jul. 2020 
espelhinho, brincos, pulseiras, sendo os dois últimos preparados também por uma iniciada da comunidade). O terreiro, nesse momento, encontrava-se na quietude necessária para a preparação dos Barquinhos de Iemanjá. Começamos a fazer, começamos a montá-los.

Fotografia 5 - O preparo dos barcos com merengue, cocada, quindim e outros elementos que os compóem

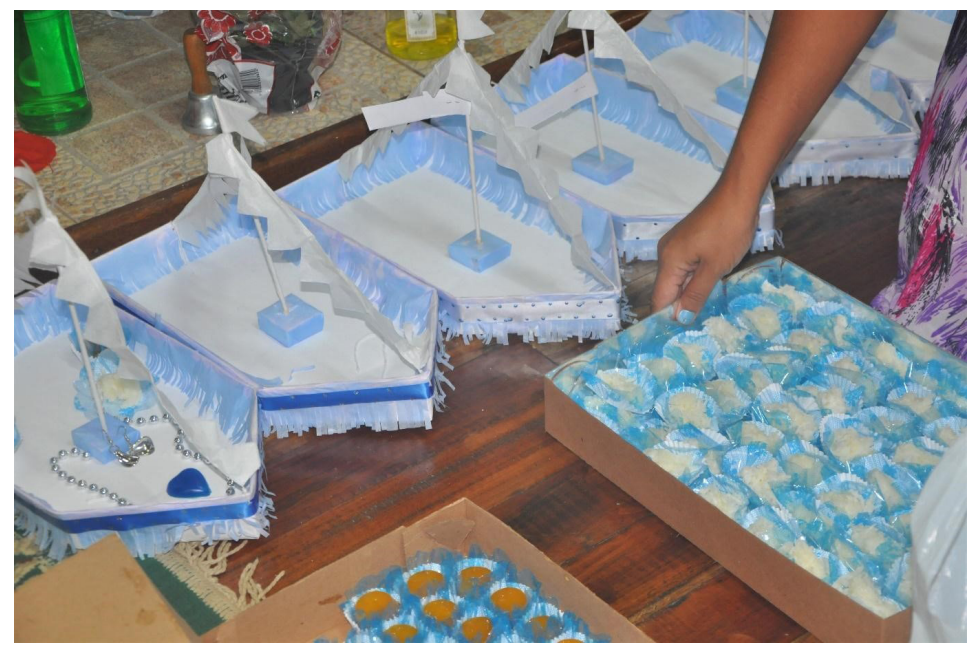

Fotografia 6 - Barquinho de Iemanjá em seu arranjo de cores e disposiçôes

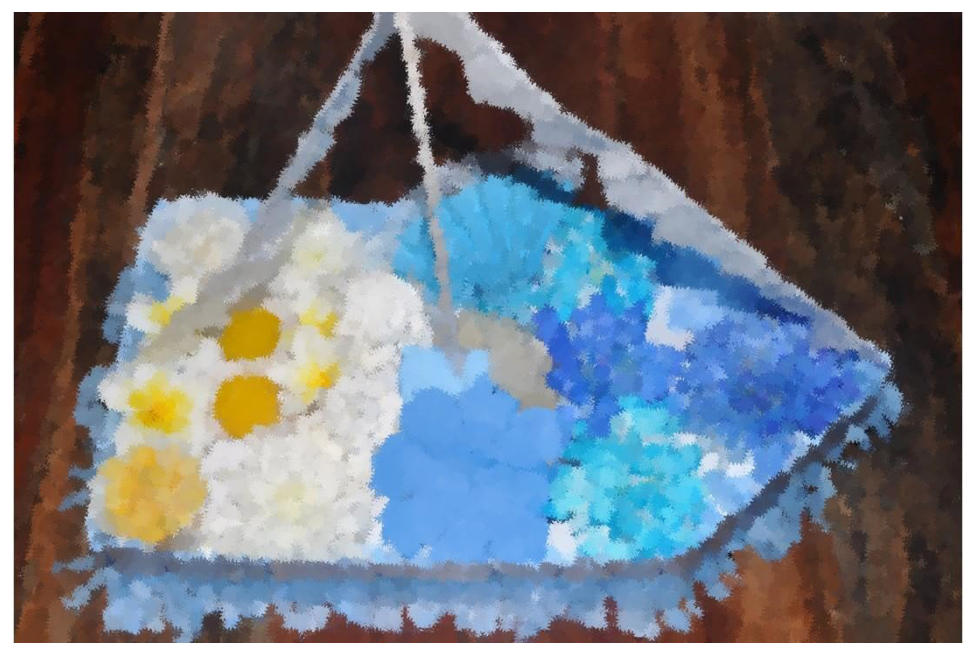

Debates do NER, Porto Alegre, ANo 20, N. 37, P. 255-269, JAN./JUl. 2020 
Quando finalizamos os barquinhos, com seus arranjos de cores como se pode observar na fotografia acima ${ }^{10}$, eles foram colocados, um a um, no chão junto ao Barco dos Pais. Esse consiste em um barco azul de madeira com um pouco mais de um metro de comprimento, o qual leva determinadas imagens de gesso também até a praia, onde são, inclusive, fortificadas energeticamente. Por fim, ao lado do Barco dos Pais, assim como atrás dele, colocamos os Barquinhos de Iemanjá já finalizados em carreiras de números pares.

Fotografia 7 - Barco dos Pais no centro do saláo e diante da porta, seguido dos Barquinhos de Iemanjá, formando uma composição, uma "frente" para a homenagem

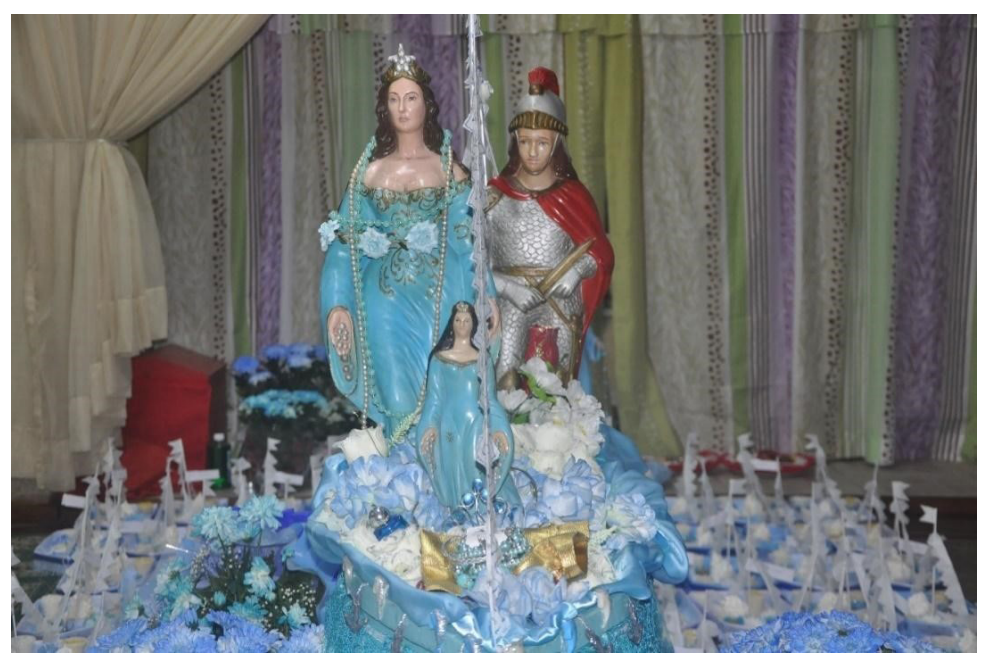

Após os barquinhos e os demais elementos que compóem a homenagem à Iemanjá estarem todos prontos, o restante da tarde seguiu com a chegada de mais e mais pessoas para se juntarem à excursão da comunidade-terreiro (filhos, familiares, amigos e vizinhos). Do mesmo modo, diferentes tipos

${ }^{10}$ De acordo com os princípios da comunidade, após o Barquinho de Iemanjá estar pronto e disposto no chão ele já é e porta a presença vigorosa do sagrado (Sodré, 2015). Nessa direçấo, para o sagrado náo ser revelado (solicitaçáo da comunidade), foi aplicado um efeito de marcação/esmaecimento na fotografia.

Debates do NER, Porto Alegre, ano 20, N. 37, P. 255-269, JAN./JUl. 2020 
de flores, rosas, crisântemos, brancos e azuis, foram sendo trazidos para a homenagem compondo um conjunto de presentes à Iemanjá, ao passo que velas também foram sendo acesas para "iluminar o ritual", nossos caminhos, percursos e movimentos.

Fotografia 8 - Crisântemos para Iemanjá

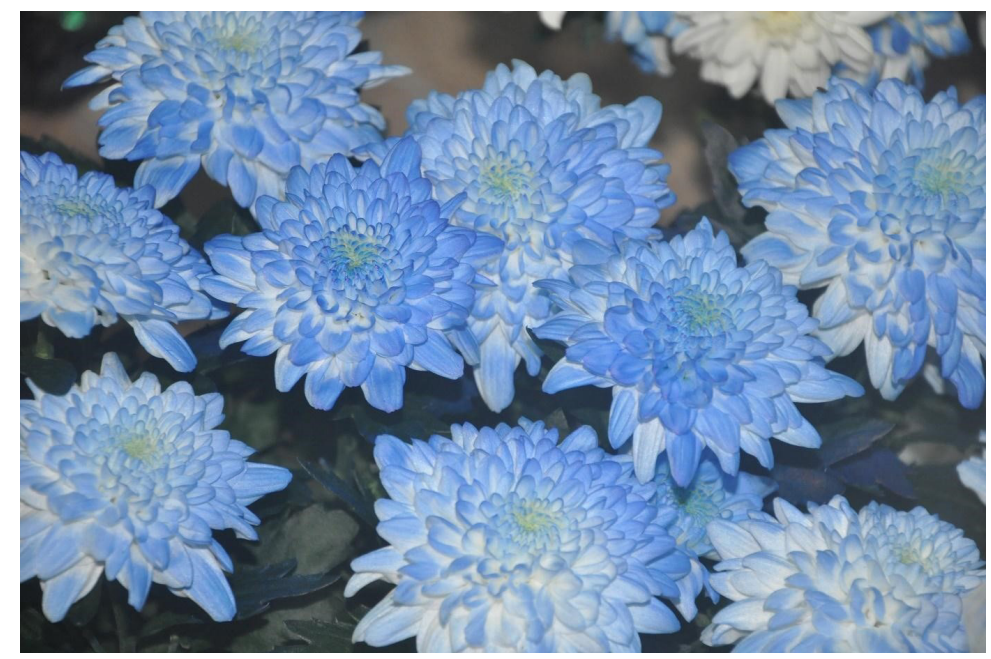

Fotografia 9 - Flores que também irão compor os Barquinhos de Iemanjá

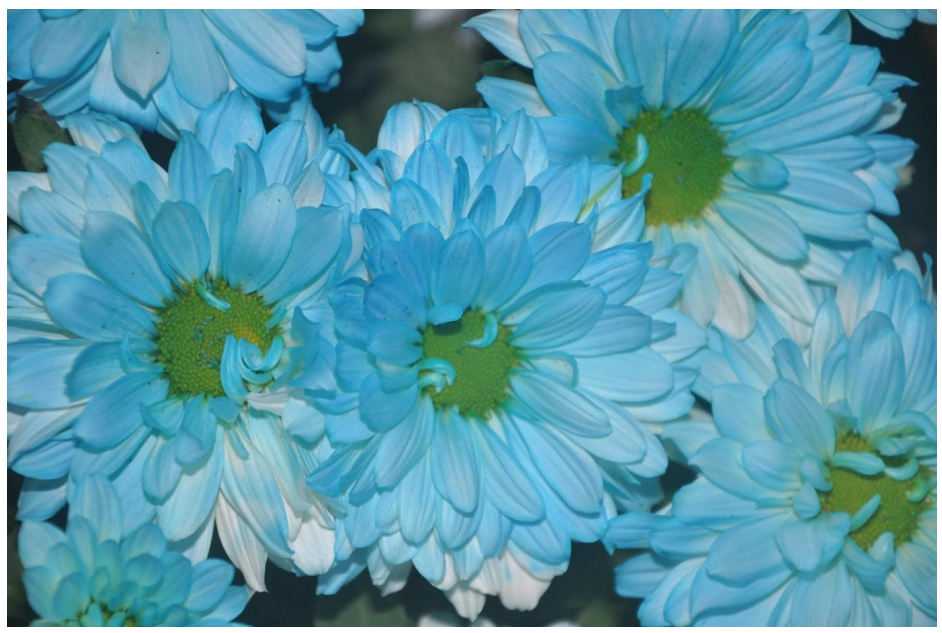

Debates do NER, Porto Alegre, ano 20, N. 37, P. 255-269, JAN./Jul. 2020 
Fotografia 10 - Para iluminar o ritual

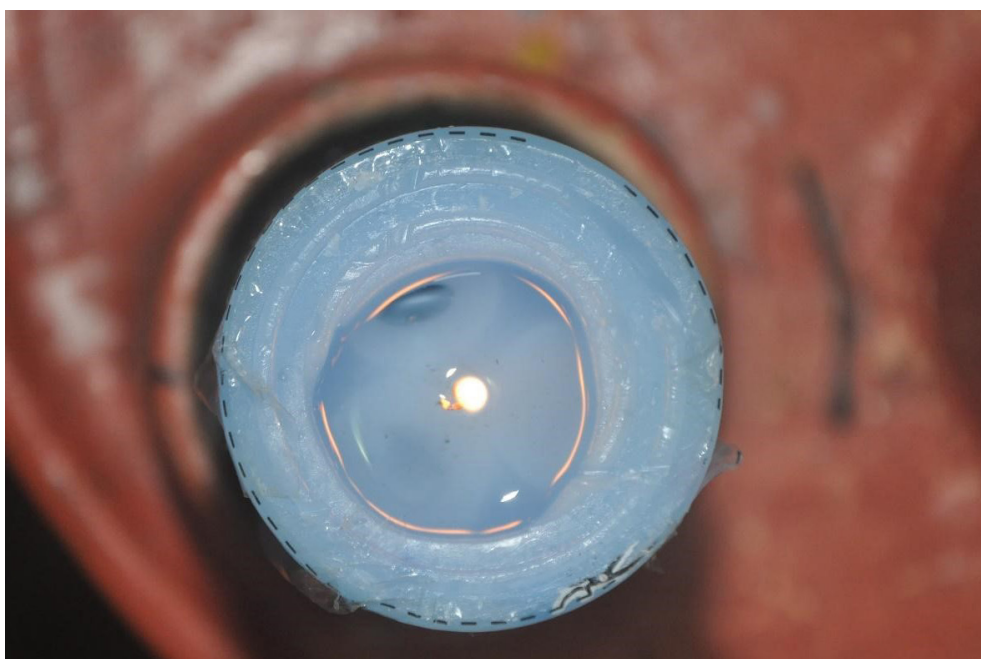

Fotografia 11 - Velas acesas no congá do terreiro

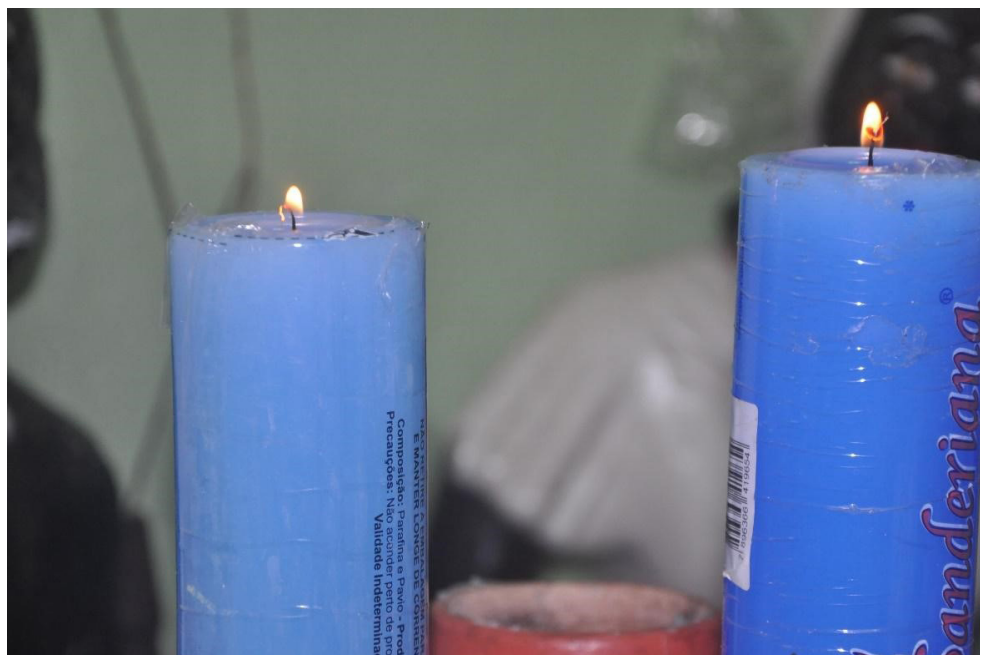

Para a excursão até o mar, o Barco dos Pais foi calmamente acomodado no corredor do ônibus e os barquinhos foram delicadamente alojados no bagageiro de teto. No percurso, todos os filhos cantaram animados os pontos 
que foram sendo entoados até o início da estrada que nos levou ao mar. Desde a rua, pessoas nos escutaram e observaram nossa passagem.

Vamos ao mar, vamos à Santa. Chegamos à cidade litorânea já noite e, após o cauteloso manobrar do ônibus por pequenas ruas de paralelepípedo, estacionamos no local em que os presentes encontram as águas salgadas do mar em um culto de umbanda. Realizamos as homenagens todos os anos no mesmo lugar: junto ao monumento de Iemanjá na praia de Santa Terezinha, em Imbé/RS.

Fotografia 12 - Monumento de Iemanjá na praia de Santa Terezinha, Imbé, RS

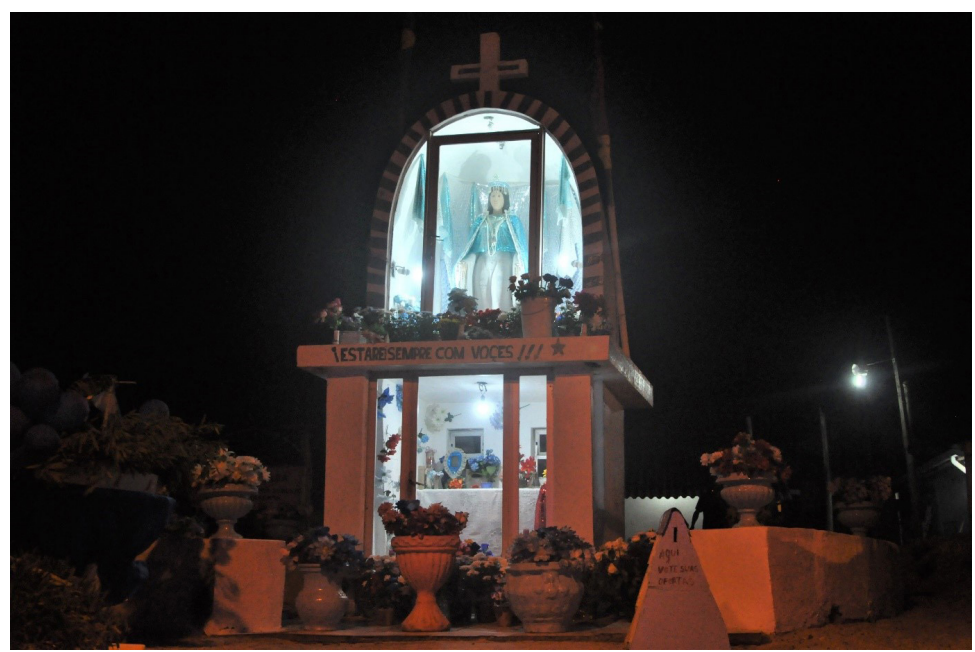

Descemos e descarregamos do veículo tudo o que é necessário para a realização da festa. Logo observamos no local um pequeno grupo de pessoas que já aguardava o ritual. Próximo à rampa que dá acesso ao monumento da santa, formamos uma mesa, dispondo uma toalha branca sobre o chão de areia. Nela colocamos, de frente para o mar, e de maneira agrupada e organizada, conforme Mãe Ângela nos ensinou, o Barco dos Pais, os barquinhos e as flores. Ao redor da mesa, velas são acesas e persistiram assim, resistindo fortemente às intempéries de uma noite na beira da praia. Mãe Ângela nos diz: "vamos fazer uma homenagem simples e bonita". 
Fotografia 13 - Mesa dos pais, frente de homenagem a Iemanjá na praia de Santa Terezinha, Imbé, RS

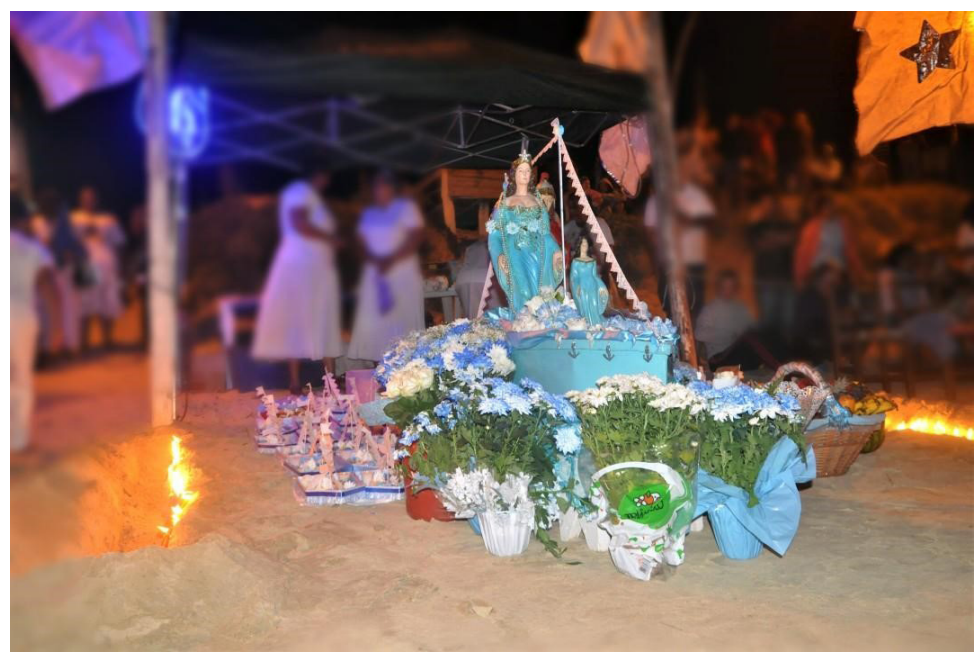

Com a proximidade do final da homenagem é hora de cada iniciado levar os presentes em uma caminhada rumo às águas, e os Barquinhos de Iemanjá encontrarem o mar, momento em que a fotografia não é permitida. Tal como descreve Sodré (2015), somos uma alteridade próxima e sedutora que não entrega o segredo que permanece na/da comunidade-terreiro.

Depois de algumas horas após a homenagem é possível ainda observar na beira da praia alguns elementos que a compuseram. Assim, um pequeno brinco azul, algumas flores e um pedaço de melancia - uma das frutas de Iemanjá (Oro; Anjos, 2009) - na areia são a presença vigorosa do sagrado que se presentifica em cada fevereiro na rota dos Barquinhos de Iemanjá. 
Fotografia 14 - Rosa de Iemanjá disposta na beira da praia após o ritual

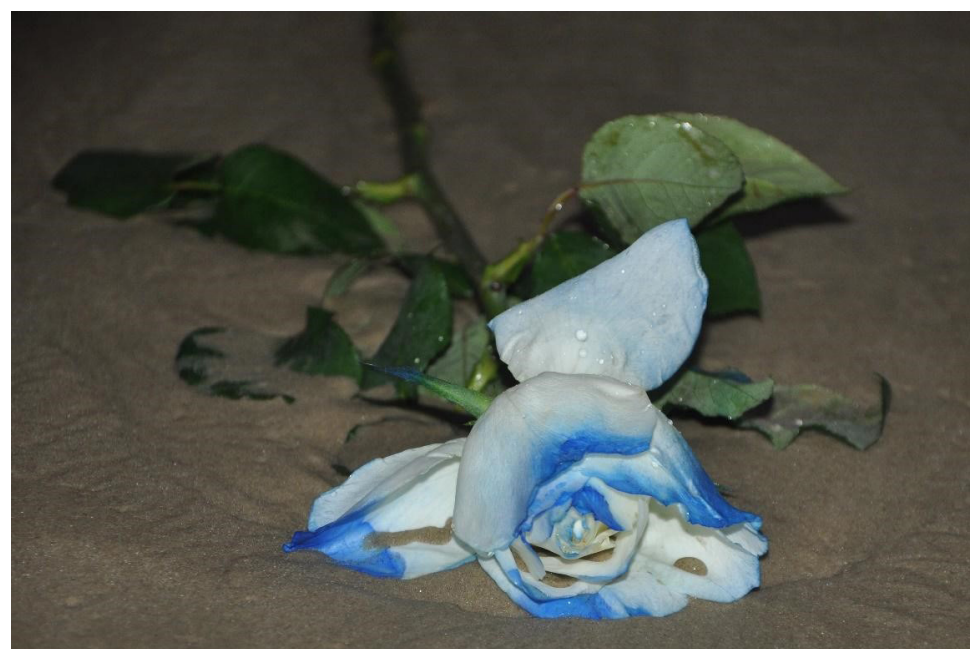

Fotografia 15 - Brinco e conchas de Iemanjá na beira da praia

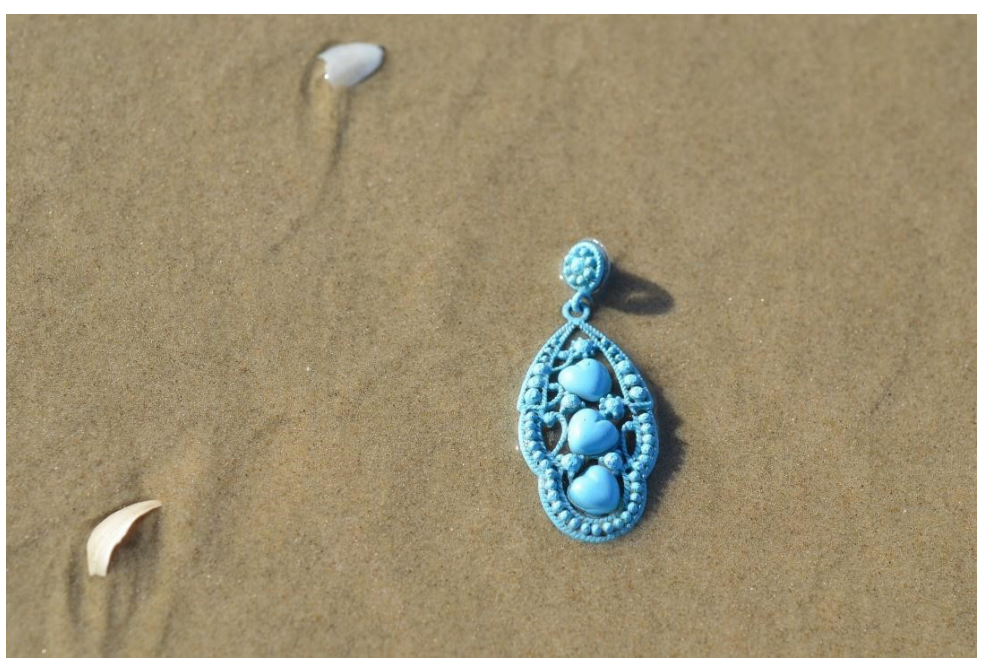


Fotografia 16 - Melancia de Iemanjá

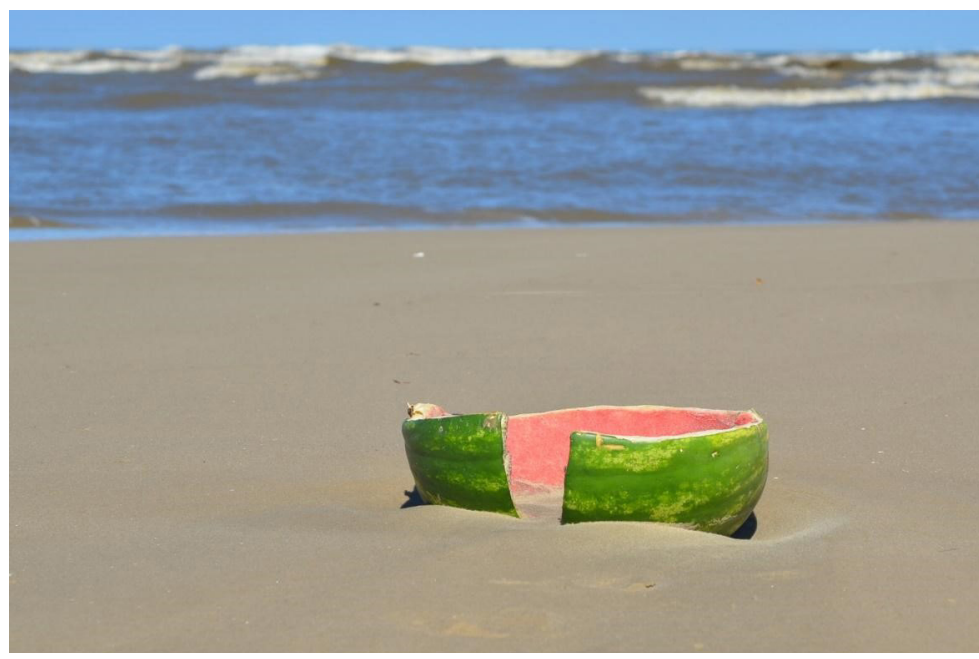

\section{REFERENNCIAS}

CORRÊA, Norton Figueiredo. Panorama das religióes afro-brasileiras do Rio Grande do Sul. In: ORO, Ari Pedro (org.). As religióes afro-brasileiras do Rio Grande do Sul. 1. ed. Porto Alegre: Editora da UFRGS, 1994. p. 19-46. ORO, Ari Pedro; ANJOS, José Carlos Gomes dos. Festa de Nossa Senhora dos Navegantes em Porto Alegre: sincretismo entre Maria e Iemanjá. Porto Alegre: Secretaria Municipal da Cultura: Editora da Cidade, 2009.

ORO, Ari Pedro. As religióes afro-brasileiras do Rio Grande do Sul. Debates do NER, Porto Alegre, ano 9, n. 13 p. 9-23, 2008. Disponível em: https://seer. ufrgs.br/debatesdoner/article/viewFile/5244/2975. Acesso em: 14 nov. 2019. SODRÉ, Muniz. Claros e escuros: identidade, povo, mídia e cotas no Brasil. 3. ed. Petrópolis: Vozes, 2015. 
VALLADO, Armando. Iemanjá, a mãe poderosa. Le Monde Diplomatique Brasil, Brasil, ed. 31, 3 fev. 2010. Cultura Popular. Disponível em: https:// diplomatique.org.br/iemanja-a-mae-poderosa/. Acesso em: 26 set. 2019.

Recebido em: 18/12/2019 Aprovado em: 06/07/2020 
